\title{
NI LIBERTAD NI RELIGIÓN: LA LIBERTAD RELIGIOSA EN CONTEXTOS CARCELARIOS EN LOS ESTADOS UNIDOS
}

\author{
Neither freedom nor religion: Religious freedom \\ in the prison context in the United States of America
}

\author{
LUIS ALEJANDRO SILVA IRARRÁZAVAL \\ Universidad de los Andes \\ Isilva@uandes.cl
}

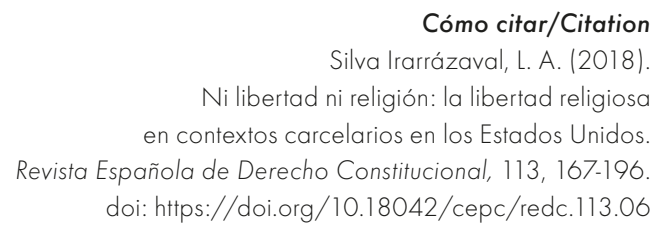

\section{Resumen}

La protección de la libertad religiosa está condicionada por lo que se entienda como religión. En los Estados Unidos, el concepto de religión se ha ampliado tanto que amenaza con volverse irrelevante. Un escenario en que puede verificarse el deterioro conceptual de la religión en cuanto categoría constitucional y su consecuente debilitamiento como criterio para resolver conflictos de libertad religiosa es el de las cárceles en los Estados Unidos. En este artículo se analiza la jurisprudencia sobre las excepciones al interior de las cárceles apoyadas en motivos religiosos. Específicamente, se observa que la fórmula para decidir dichas exepciones, y que articula una parte subjetiva (conciencia individual) y una parte objetiva (la administración de cárceles), es indiferente a la conciencia individual y, en cambio, conduce a que los conflictos se decidan en función de criterios sobre gestión penitenciaria.

\section{Palabras clave}

Libertad religiosa; objeción de conciencia; derechos fundamentales. 


\begin{abstract}
To understand what religion means is critical to determine the scope of protection of the First Amendment of the Constitution. In the United States of America, the concept of the religion has been watered down up to the point of becoming irrelevant under the light of its constitutional warrant. This conceptual detriment of religion as a constitutional category can be verifyed in the province of prision litigation. In this paper, we submitt to analysis the caselaw of religious accommodations for those within the prison walls. Specifically, we observe that judicial practice overlooks individual's religious beliefs when it comes to guarantee a First Amendment claim. Instead, the adjudication process by the judicary hinges on much more secular criteria — those of prisions administration.
\end{abstract}

Keywords

Religious freedom; religious accommodations; fundamental rights. 


\section{SUMARIO}

I. INTRODUCCIÓN. II. LA LIBERTAD RELIGIOSA Y SU PROTECCIÓN: 1. El objeto (el concepto de religión). 2. La historia. 3. La fórmula. 4 Los estándares: 4.1. El estándar de la Free Exercise Clause. 4.2 El estándar RLUIPA. III. EL JUICIO DE LA DIMENSIÓN SUBJETIVA: 1. EI test de la sustancialidad. 2. El test de la sinceridad. IV. EL JUICIO DE LA DIMENSIÓN OBJETIVA: 1. La conexión racional entre la regulación y los intereses de la prisión. 2. El impacto de la excepción en la comunidad penitenciaria. 3. El test del costo mínimo. 4. El test del interés imperioso. 5. El test de la lesividad. V. CONCLUSIÓN. BIBLIOGRAFía. JURISPRUDENCIA.

\section{INTRODUCCIÓN}

Es imposible proteger la libertad religiosa sin definir la religión. En un país como los Estados Unidos de Norteamérica, en que la definición de religión se ha ido ampliando hasta el punto de volverla indiferenciable de otras manifestaciones de lo humano merecedoras de protección constitucional (por ejemplo, asociación, expresión, igualdad), la garantía de la libertad religiosa como un bien específico se hace cada vez más difícil de justificar. Este resultado es confirmado por la jurisprudencia, en cuanto la religión y las formas de practicarla son generalmente incontrovertibles ante los jueces, decidiéndose la cuestión litigiosa en un terreno ajeno a la naturaleza de la pretensión, que debería ser si la conducta puede ampararse bajo la libertad religiosa legítimamente o no. Esta circunstancia se hace visible de manera especial en los casos en que los prisioneros demandan un reconocimiento de sus prácticas religiosas a los agentes adiministradores de las cárceles.

La tesis de este artículo es que la jurisprudencia sobre las demandas de prisioneros fundadas en la libertad religiosa refleja la debilidad de la religión en cuanto categoría constitucional. En otras palabras, la religión demuestra ser un concepto prácticamente inútil para orientar el razonamiento judicial, porque su determinación está entregada a criterios subjetivos imponderables desde una perspectiva objetiva. Una prueba elocuente del enervamiento de la religión en la defensa de su propio ejercicio es que lo casos terminan por decidirse en función de motivos relacionados con la gestión de las cárceles.

Si un preso declara que el mandamiento central de su religión es "haz como te plazca» ${ }^{1}$, ¿sobre qué bases se podrá justificar una restricción a su

1 Este era el dogma central de Gregory Koger, un prisionero miembro del Ordo Templi Orientis, asociado a la religión Thelema; véase Koger v. Bryan, 523 F.3d 789, 794 (7th Cir.2008). 
ejercicio? En un contexto en el que el carácter religioso de una idea o conducta, o la sinceridad con que se cree o practica, o el lugar que tiene dentro del sistema de creencias, es incuestionable, la justificación tiene que buscarse en un terreno distinto del religioso, dominado por la subjetividad; un terreno que ofrezca a los jueces referencias objetivas. De ordinario, este resulta ser el de la administración penitenciaria.

En la medida en que la libertad religiosa de los presos requiere pronunciarse acerca de la acomodación de disposiciones generales a sus necesidades particulares, sobre la base de una fórmula que conjuga la dimensión subjetiva de la exigencia religiosamente motivada con la dimensión objetiva de la administración penitenciaria, la decisión está indefectiblemente predeterminada a inclinarse ante las alegaciones religiosas y, en consecuencia, cualquier discusión en ese terreno es inútil para los intereses de los guardias. Luego, es en el terreno de la administración de las cárceles donde puede construirse un razonamiento para justificar la restricción del ejercicio de la libertad religiosa. Esta circunstancia, sumada a una inclinación natural por rechazar las demandas de los prisioneros por mayor libertad, convierten la litigación penitenciaria en un buen ejemplo para ilustrar la inherente debilidad de un concepto de religión que se ha ampliado hasta el punto de quedar vaciado de contenido.

Este trabajo está dividido en tres secciones, además de la introducción y la conclusión. En la primera sección se presentan las coordenadas en que se enmarca la litigación de la libertad religiosa de los prisioneros, con el propósito de identificar las dificultades para precisar el significado constitucional de la religión, intrínsecos a su sistema de protección. La segunda sección desarrolla los estándares subjetivos que deben verificarse para proteger la libertad religiosa, subrayando la tendencia congénita que los conduce a un terreno donde es imposible la discusión racional. La tercera sección desarrolla los estándares objetivos que deben cumplirse para conceder una excepción religiosa a un prisionero, caracterizando la secularidad del terreno en el que se ponderan y las ventajas que esta cualidad representa para la tarea judicial.

\section{LA LIBERTAD RELIGIOSA Y SU PROTECCIÓN}

En esta sección se desarrollan los elementos estructurantes de una de las vías por las que se protege la libertad religiosa en los Estados Unidos, la de las excepciones o acomodaciones. Esta vía apunta a conceder una excepción a la aplicación de una regla general, cuando hay motivos religiosos que obstan a su 
cumplimiento ${ }^{2}$. Las excepciones o acomodaciones religiosas se ponderan a través de una fórmula que admite diferentes gradaciones o estándares. Esta fórmula presupone en cada caso una determinada concepción de religión, cuyo ejercicio es precisamente lo que se trata de proteger. De allí que a continuación se trate de la religión en cuanto objeto de la fórmula de acomodaciones religiosas (2.1), de la historia de su protección entre los prisioneros (2.2), de la fórmula misma (2.3) y de los diferentes grados o estándares de aplicación de la fórmula (2.4).

\section{EL OBJETO (EL CONCEPTO DE RELIGIÓN)}

El libre ejercicio de la religión ha sido objeto de atención constitucional desde la fundación misma de la nación norteamericana (McDonald, 1985: 41-45). La libertad religiosa probablemente sea una de las notas más características del nuevo orden de libertades creado en 1787-1789 (Paulsen y Paulsen, 2015: 100)3. Consagrada en la Primera Enmienda de la Constitución, contempla dos garantías: el libre ejercicio de la religión (Free Exercise Clause) y la separación iglesia/Estado (Non Establishment Clause). La Free Exercise Clause se interpretó, desde el principio, como el título para la concesión de excepciones al cumplimiento de disposiciones generalmente exigibles, aunque estas se concedieran en forma restrictiva y favorecieran a las denominaciones protestantes (McConnell, 1992: 1466-1473).

La aplicación judicial de la Free Exercise Clause fue nula durante largos años ${ }^{4}$. Allí donde se aplicó, primó una concepción de la religión con exclusión de otras 5 . Aunque la religión no había sido definida, la influencia cultural del cristianismo operó como punto de referencia de la ortodoxia (McConnell et al., 2011: 761 y ss.). Sin embargo, este esquema cambió

2 La bibliografía sobre el punto es amplia. Una referencia obligada es McConnell (1985). Un argumento reciente contra esta forma de proteger la libertad religiosa en Smith (2016), quien apunta al daño que representa para la eficacia de un adecuado sistema legal.

3 Los autores destacan la «dramática expansión» que la formulación de la Primera Enmienda supuso respecto de las nociones previas de libertad religiosa (Paulsen y Paulsen, 2015: 100).

4 La primera vez que la Corte Suprema federal se pronunció sobre la Free Exercise Clause fue casi un siglo después de haberse escrito en la Constitución, en el caso Reynolds v. United States, 98 U.S. 145 (1878).

5 Por ejemplo, Mormon Church v. United States, 136 U.S. 1, 49 (1890), en que la Corte afirmó que «[la poligamia] es contraria al espíritu del Cristianismo y de la civilización que el Cristianismo ha creado en el mundo occidental». 
radicalmente en el lapso de dos décadas. La sentencia United States v. Ballard definió que la Primera Enmienda prohibe examinar «la verdad o veracidad [...] de creencias o doctrinas religiosas» ${ }^{6}$. Y justificó lo anterior diciendo que, puesto que «los hombres pueden creer aquello que no pueden probar, no puede pedírseles prueba de sus creencias o doctrinas religiosas» ${ }^{7}$. Entenderlo de otra manera sería privar de significado la Primera Enmienda, porque "si alguien puede ser enviado a la cárcel debido a que un jurado [...] halla [ciertas creencias] falsas, poco es lo que quedaría de la libertad religiosa ${ }^{8}$. Dos décadas más tarde, la sentencia United States $v$. Seeger igualó las convicciones seculares con las convicciones religiosas, declarando que un objetor de conciencia por motivos éticos podría eximirse del servicio militar si es que «la creencia alegada ocupa en la vida del demandante el mismo lugar que la fe en Dios tiene en la vida de alguien claramente calificado para la excepción ${ }^{9}$. Desarrollando el contenido de la sentencia Ballard, la Corte Suprema agregó que lo importante es «si las creencias profesadas [por el demandante] son sinceramente sostenidas y si es que son religiosas, en su propia cosmovisión ${ }^{10}$. Una tercera decisión, determinante en la expansión de la libertad religiosa, fue Thomas v. Review Board of the Indiana Employment Security Division ${ }^{11}$. En la encrucijada de juzgar si la negativa de un testigo de Jehová a trabajar en la fabricación de torretas de tanques merecía el beneficio estatal para los desempleados, la Corte renunció a zanjar las diferencias de interpretación que el demandante tenía con algún correligionario, para quien trabajar en la fabricación de armas no era contrario a su religión. El motivo que adujo el tribunal para justificar su omisión fue: «Está fuera de la función judicial y de la competencia de los tribunales inquirir si es el demandante o su correligionario quien comprende más correctamente los mandamientos de su fe. Las Cortes no son árbitros de interpretaciones escriturísticas» ${ }^{12}$.

Las sentencias Ballard, Seeger y Thomas marcan el derrotero que ha seguido la libertad religiosa: privada por los jueces de referencias objetivas que permitan identificar sus contornos, los alcances de la Free Exercise Clause se extienden potencialmente a toda demanda fundada en una convicción sincera

\footnotetext{
6 United States v. Ballard, 322 U.S. 78, 86 (1944).

7 United States v. Ballard, 322 U.S. 78, 86 (1944).

8 United States v. Ballard, 322 U.S. 78, 87 (1944).

$9 \quad$ United States v. Seeger 380 U.S. 163, 187 (1965).

10 United States v. Seeger 380 U.S. 163, 185 (1965).

11 Thomas v. Indiana Employment Security Division 450 U.S. 707 (1981).

12 Thomas v. Indiana Employment Security Division 450 U.S. 707, 716 (1981).
} 
y profunda que comprometa a su conciencia. ${ }^{13}$ Aunque en 1990 la sentencia Smith vino a contener esta expansión en la litigación constitucional, dicha concepción de la libertad religiosa prevaleció en la legislación ${ }^{14}$.

\section{LA HISTORIA}

Hasta 1950, los presos apenas conocieron la protección de sus derechos fundamentales, por no mencionar su libertad religiosa (Haas, 1977: 795-797). Estos llegaron a ser considerados como «esclavos del Estado» por algún tribunal. ${ }^{15}$ Los tribunales estaban poco inclinados a aplicar la Constitución en contra de los representantes del Estado, especialmente tratándose de quienes regentan los establecimientos penitenciarios. Esto, en parte, «debido a sus aprensiones respecto del federalismo y la separación de los poderes, pero también por la poca familiaridad con las ciencias penitenciarias [penología] y la administración de las prisiones» (Solove, 1996: 466) ${ }^{16}$. En palabras de una corte de apelaciones, «no es función de los jueces velar por el trato y la disciplina de los presos en las cárceles»" $»^{17}$. Este período puede ser calificado como el de la doctrina «de las manos atrás» (Cooper, 1995: 328; Solove, 1996: 466).

En la década de los sesenta la situación comenzó a cambiar (Gaubatz, 2005: 507; Solove, 1996: 466). La sentencia Cooper v. Pate ${ }^{18}$, en la que se reconoció la legitimidad de los presos para demandar protección federal al ejercicio

13 Sullivan (2005: 100-101) se pregunta en función de estos y otros casos análogos: "¿Quién está llamado a decir qué es la religión para efectos legales en los Estados Unidos? ¿Deberían las cortes o los legisladores tener competencia alguna para hacerlo?». Y responde sin resolver: "Una lectura de la Primera Enmienda sugeriría que cuando el Estado se involucra en la definición de lo que es la religión, viola su neutralidad en materias religiosas. El resultado será necesariamente discriminatorio. Definir es excluir, y excluir es discriminar».

14 Employment Division, Department of Human Resources of Oregon v. Smith, 494 U.S. 872 (1990). Véanse infra notas 29 y ss.

15 Ruffin v. Commonwealth, 62 Va. 790, 795-96 (1871): «Mientras dure el tiempo de su condena en la cárcel [un convicto] se halla en un estado de servidumbre penal para con el Estado [...]. Durante ese tiempo es un esclavo del Estado. Es un civiliter mortuus y su patrimonio, si es que tiene alguno, es administrado como el de alguien que ha muerto».

16 Las aprensiones de los jueces respecto del federalismo se deben a que las cárceles son algunas estatales y otras federales, no debiendo intervenir los jueces estatales en las federales ni viceversa.

17 Haas v. United States, 344 F.2d 56, 67 (8th Cir. 1965).

18 Cooper v. Pate, 378 U.S. 546 (1964). 
de su libertad religiosa, representa «el comienzo del fin de la doctrina "de las manos atrás” (Cooper, 1995: 328) ${ }^{19}$. En 1972 la Corte Suprema falló por primera vez en favor de la libertad religiosa de un preso, con la sentencia Cruz v. Beto, declarando que impedir a un prisionero budista el acceso a las posibilidades ofrecidas a los prisioneros de otras religiones era inconstitucional ${ }^{20}$. Se ha dicho que «en los 15 ańos que siguieron a la decisión Cruz v. Beto, los presos disfrutaron del más alto nivel de protección de su libertad religiosa bajo la Primera Enmienda en la historia de la nación» (Gaubatz, 2005: 507) ${ }^{21}$. En cualquier caso, el estándar de exigencia aplicado a las autoridades penitenciarias por los tribunales no fue uniforme (Cooper, 1995: 328), aunque sí más deferente que el aplicado al poder estatal fuera de la prisión (Gaubatz, 2005: 507).

Este periodo de una ostensible preocupación hacia los presos habría visto su fin con la sentencia Turner v. Safley (Gaubatz, 2005: 507)22. En ella, la Corte Suprema declinó juzgar ciertas normativas penitenciarias con un criterio estricto, contentándose con que ellas sirvan para un interés penológico legítimo. Esta decisión, que estableció el estándar para la protección constitucional de los derechos fundamentales de los presos, fue refrendada por O'Lone v. Estate of Shabazz $z^{23}$, en lo tocante a la libertad religiosa ${ }^{24}$. El estándar fijado por las sentencias Turner y

19 Gaubatz (2005: 322) y Solove (1996: 467), en cambio, atribuyen este momento a la sentencia Cruz v. Beto.

20 Cruz v. Beto, 405 U.S. 319 (1972).

21 Solove (1996: 468) modera esta interpretación advirtiendo que la Corte Suprema mantuvo un alto grado de deferencia hacia los agentes penitenciarios, durante toda la década que siguió a Cruz v. Beto.

22 Turner v. Safley, 482 U.S. 78 (1987). De nuevo, Solove (1996: 470) es menos dramático: «Las sentencias Turner y O'Lone no significaron un retroceso en la protección de los derechos de los presos: ellas simplemente clarificaron lo que muchas cortes ya venían haciendo». Sin embargo, esto parece estar en conflicto con las memorias legislativas: tanto el House Report como el Senate Report registran que la jurisprudencia pre-O'Lone había establecido un exigente estándar de escrutinio para con las regulaciones penitenciarias (Committee on the Judiciary United States Senate, 1993; Committee on the Judiciary United States House of Representatives, 1993: 7). Solove (1996: 473) califica de impropia esta caracterización de la jurisprudencia pre-O’Lone.

23 O'Lone v. Estate of Shabazz, 482 U.S. 342 (1987). En este caso, la Corte rechazó la impugnación por inconstitucionalidad contra unas normas penitenciarias que, en la práctica, impedían a un grupo de prisioneros musulmanes participar en el Jumu’Ha, porque la deferencia debida a la administración de cárceles requiere que las regulaciones estén racionalmente ordenadas a un fin penológico legítimo.

24 O'Lone estableció el test que entonces pasaría a aplicarse en la materia, alineando así a los tribunales inferiores (Cooper, 1995: 328). «En muchos sentidos, O'Lone vino a 
O'Lone estaría consagrando «el grado de escrutinio al nivel más bajo de los usados por los tribunales; un nivel tan precario y deferente [para con las regulaciones gubernamentales] que se aproximó a la doctrina de "las manos atrás" (Solove, 1996: 470). O'Lone es la especificación de una doctrina más amplia en relación a los derechos de los presos, que se basa en las siguientes tres premisas acuñadas por la Corte Suprema: a) los presos conservan sus derechos constitucionales; ${ }^{25}$ b) los derechos constitucionales de los presos están limitados por las características propias del sistema penitenciario, ${ }^{26} \mathrm{c}$ ) las políticas penitenciarias han de ser tratadas con un alto grado de deferencia por parte de los jueces. ${ }^{27}$

Aunque la sentencia Employment Division, Department of Human Resources of Oregon $v$. Smith restringió el estándar de protección de la libertad religiosa en los Estados Unidos, es discutible el impacto que tuvo en la litigación de la libertad religiosa de los presos ${ }^{28}$. En cualquier caso, se estimó que la ley con que el Congreso repuso el estándar previo a la sentencia Smith, la Religious Freedom Restoration Act (RFRA) habría de beneficiarlos (Gaubatz, 2005: $509)^{29}$. Si bien durante su aplicación la RFRA fue entendida en general como

ser el primer paso de la Corte Suprema en su distanciamiento respecto de la libertad religiosa de los presos, y que luego se extendería incluso más allá del ámbito de esa libertad» (Gaubatz, 2005: 508); el autor citado está haciendo referencia a la decisión Employment Division, Department of Human Resources of Oregon vs. Smith, 494 U.S. 872 (1990).

25 Pell v. Procunier, 417 U.S. 817 (1974).

26 Price v. Johnston, 334 U.S. 266 (1948).

27 Jones v. North Carolina Prisoners' Labor Union, Inc., 433 U.S. 119 (1977). Sobre las tres premisas, véase Cooper (1995: 328-329).

28 Véase, por ejemplo, la afirmación de Douglas Laycock en la discusión parlamentaria de lo que terminaría siendo la RLUIPA: «Algunas cortes han asumido tácitamente que los casos de las prisiones siguen rigiéndose por Turner v. Safley y que la sentencia Employment Division v. Smith no se les aplica» (Committee on the Judiciary United States Senate, 1997: 66-67). Véase también Cooper (1995: 327 y 331).

29 En el mismo sentido, Cooper (1995: 332) indica que «la historia de la ley atestigua que la intención del Congreso con RFRA era superar O'Lone»; y Solove (1996: 471) que «Smith no fue el único objetivo de RFRA, sino también O'Lone». «RFRA supuso un rechazo tácito de O'Lone por la vía de no preservar la excepción de O’Lone para las prisiones» (Brady, 2011: 1447). Durante la discusión parlamentaria, quedó claro que la RFRA apuntaba también a fortalecer la protección de la libertad religiosa de los presos: «En cuanto aplicada en el contexto carcelario, la intención de esta ley es restaurar la protección tradicionalmente reconocida a los prisioneros para que practiquen su religión, y que fue debilitada por la sentencia O'Lone v. Estate of Shabazz» (Committee on the Judiciary United States Senate, 1993: 9). En sentido estricto, la 
un progreso en la protección de la libertad religiosa de los presos (Cooper, 1995: 325-326) ${ }^{30}$, las estadísticas no respaldan esta idea (Lupu, 1998) ${ }^{31}$. Para colmo, a los cuatro años de haber entrado en vigor la RFRA fue declarada inconstitucional en el caso City of Boerne v. Flores ${ }^{32}$.

La Religious Land Use and Institutionalized Persons Act (RLUIPA), del año 2000, fue la reacción del Congreso contra la sentencia City of Boerne, y tuvo por objetivo — como antes la RFRA— restaurar el estándar de la Free Exercise Clause anterior a la sentencia Smith, impidiendo así que los jueces apliquen el estándar de los casos Turner y O'Lone en la litigación penitenciaria ${ }^{33}$.

\section{LA FÓRMULA}

Desde la década de los sesenta, la historia de la Free Exercise Clause puede ser caracterizada como las idas y venidas de la doctrina de las excepciones religiosas. Esta doctrina apunta al conflicto, cada vez más frecuente, entre la conciencia individual y las regulaciones gubernamentales, con el propósito de indicar el justo medio entre la deferencia para con los derechos del individuo y las necesidades del Gobierno (McConnell, 1992: 739) ${ }^{34}$. Desde el punto de vista del bien común, esta es una tarea sensible y delicada. Como ha señalado McConnell (1992: 736), «el aspecto más difícil del balance requerido por la

RFRA no representa el estándar de la Free Exercise Clause, porque la sentencia Smith es un obstáculo constitucional que no puede ser removido por la legislación ordinaria. La RFRA es una ley, una superley si se quiere (Paulsen, 1995), cuyo estándar es diferente al constitucional de la Free Exercise Clause.

Véase también Committee on the Judiciary United States Senate (1997: 37-79).

31 Las cortes siguieron decidiendo los casos con el estándar O’Lone (Solove, 1996: 474).

32 City of Boerne v. Flores, 521 U.S. 507 (1997).

33 «RLUIPA rechazó explícitamente a O’Lone por la vía de extender abiertamente el test de la carga sustancial a los presos» (Brady, 2011: 1447). Gaubatz (2005: 510) señala tres factores que prueban la finalidad de la RLUIPA de beneficiar a los presos. Aquí resulta oportuno señalar que la aplicación de RLUIPA es armónica con la aplicación de la Prison Litigation Reform Act (PLRA), aprobada en 1996 para disminuir los índices de litigación judicial: las restricciones procedimentales impuestas por la PLRA son condicionantes formales que dejan intacta la substancia de la RLUIPA, que es la protección de la libertad religiosa. Debo este punto Michael S. Paulsen.

34 La excepción religiosa tambien puede ser entendida como una palanca entre las minorías y las mayorías políticas (Tushnet, 1988); o el punto de articulación entre las prácticas religiosas y el bien común (Eisgruber y Sager, 2009: 87) o entre el reconocimiento de los intereses individuales y de los intereses colectivos (Eisgruber y Sager, 2009: 279). 
libertad religiosa, es la valoración del peso que debe dársele a la aplicación de las medidas del gobierno respecto de un objetor de conciencia».

En la adjudicación de excepciones religiosas, los jueces utilizan una fórmula que refleja en su estructura los intereses en conflicto. Una de las partes de esta fórmula sirve para ponderar el interés del individuo, expresado a través de la libertad religiosa, y la otra para ponderar el interés de la autoridad, expresado a través de regulaciones de aplicación general. A la primera la calificaremos como subjetiva, por estar centrada en esa dimensión tan personal que es la religión. A la segunda la calificaremos de objetiva, porque busca comprobar el cumplimiento de determinadas condiciones exigibles a las normas de carácter general.

Aunque la fórmula para resolver las acomodaciones religiosas tiene una estructura única, compuesta de una parte subjetiva y otra objetiva, su aplicación admite diferentes gradaciones, según cuál sea el estándar que se utilice. Estas diferencias, sin embargo, se alojan en la parte objetiva; los criterios para juzgar la libertad religiosa, en cambio, son siempre los mismos: la parte subjetiva permanece invariable.

\section{LOS ESTÁNDARES}

Los estándares para decidir las excepciones religiosas varían entre ellos de acuerdo al grado de deferencia con que las regulaciones gubernamentales deben ser examinadas por los tribunales. Así, a mayor deferencia para con las autoridades, mayor dificultad para obtener una excepción; a menor deferencia, menor dificultad. La misma dinámica puede formularse en términos del grado de escrutinio con que se juzgan las regulaciones: cuanto más estricto sea el escrutinio, más fácil es obtener una excepción. Y viceversa.

Dos son los estándares aplicables a los casos de libertad religiosa de los prisioneros: el de la Free Exercise Clause y el de la RLUIPA. ${ }^{35}$

\subsection{El estándar de la Free Exercise Clause}

El estándar de protección de la libertad religiosa en las prisiones es diferente del que se aplica a las personas libres; mucho menos favorable, por

35 La RFRA tuvo aplicación general en los casos de prisioneros hasta que su aplicación a los estados fue declarada inconstitucional, en 1996. Véanse infra notas 29 y ss. Desde que la mayor parte de los casos ocurren en prisiones estatales y no federales (Scalia, 2002), la RFRA es aplicada ahora muy rara vez. 
supuesto. Este estándar es una combinación de dos líneas jurisprudenciales. La parte subjetiva corresponde a la línea fijada por las sentencias Ballard, Seeger y Thomas, y la parte objetiva corresponder al precedente establecido por las sentencias Turner y O'Lone. Esto significa que el estándar actual de la Free Exercise Clause requiere, por una parte, que las creencias del preso sean sinceras y, de acuerdo a su propia cosmovisión, religiosas ${ }^{36}$; y de otra, que las regulaciones penitenciarias estén justificadas por un interés penológico legítimo.

El interés penológico legítimo es un criterio para juzgar la conformidad de una regulación penitenciaria con los intereses de la administración carcelaria, tales como higene, integridad (safety) de las personas y seguridad. Turner v. Safley estableció cuatro criterios para guiar a los jueces en la evaluación de la legitimidad de una regulación penitenciaria: 1) la existencia de una conexión racional entre la regulación y los intereses de la prisión; 2) la existencia de medios alternativos para que el preso pueda practicar su religión; 3) el impacto que genera la excepción en otros prisioneros, en los agentes penitenciarios (funcionarios de prisiones) y en las instalaciones carcelarias; 4) la existencia de opciones para acomodarse a la libertad religiosa del preso que no añadan más que costos mínimos (de minimis) a los medios necesarios para alcanzar los objetivos de la prisión.

Los criterios de Turner fueron pensados para determinar una condición objetiva: cómo una política penitenciaria sirve a los intereses de la cárcel. En el establecimiento de esta condición, los jueces no deben eludir absolutamente las consideraciones religiosas, pero el énfasis está en determinar la conformidad de una regulación secular con unos intereses también seculares ${ }^{37}$.

\subsection{El estándar RLUIPA}

La sección 3 de la RLUIPA replica la estructura y redacción de la RFRA, porque su propósito es el $\mathrm{mismo}^{38}$. Sin embargo, pese a la similitud, la

36 Por ejemplo, Shakur v. Schriro, 514 F.3d 878 (9th Cir. 2008): «Para que una creencia pueda servir como fundamento de un cuestionamiento viable en contra de una regulación carcelaria, esa creencia tiene que estar sinceramente sostenida por el prisionero y enraizada en convicciones religiosas».

37 Palmer (2010: 124-125) desarrolla los intereses más frecuentemente invocados (consideraciones económicas, disciplinarias, de seguridad y discrecionalidad administrativa) y reconoce que si los oficiales de la prisión logran demostrar que las restricciones se apoyan en alguno de ellos, los tribunales les concederán la razón.

3842 U.S.C.A. par. 2000cc-1: «(a) General rule. No government shall impose a substantial burden on the religious exercise of a person residing in or confined to an 
RLUIPA introdujo una importante innovación. Basándose en la experiencia de la RFRA ${ }^{39}$, la RLUIPA ofrece una definición de lo que debe entenderse por religious exercise: cualquier práctica de la religión, con independencia de su carácter obligatorio o de su centralidad en el sistema de creencias religiosas. ${ }^{40}$

La RLUIPA es el camino por el cual el estándar construido por la jurisprudencia anterior a Smith para los ciudadanos libres se cuela dentro de las prisiones hoy. Para tener éxito invocando la RLUIPA, los demandantes deben probar que su libertad religiosa ha sido restringida substancialmente por una regulación penitenciaria, a menos de que dicha regulación sea el medio menos lesivo para satisfacer un interés penitenciario imperioso.

Puesto que es habitual que la RLUIPA sea invocada junto con la Constitución (Free Exercise Clause), y puesto que ambos estándares comparten los mismos criterios subjetivos, hay que destacar las diferencias que median entre las partes objetivas de cada uno de estos dos estándares. En primer lugar, la RLUIPA requiere que el interés gubernamental sea imperioso, mientras que la Free Exercise Clause requiere que el interés penológico sea legítimo. La calificación del interés denota que el primero es más estricto con la autoridad que el de la Free Exercise Clause. En segundo lugar, la RLUIPA requiere que las regulaciones penitenciarias sean el medio menos lesivo para alcanzar el objetivo declarado, mientras que la Free Exercise Clause se satisface con que la regulación sea coherente con el fin declarado y deje alguna alternativa para practicar la religión.

\section{EL JUICIO DE LA DIMENSIÓN SUBJETIVA}

La dimensión subjetiva de la fórmula para decidir una excepción religiosa consiste, esencialmente, en determinar, en primer lugar, si la conducta afectada por la autoridad es religiosa o está religiosamente motivada y, en segundo lugar, si el grado de afectación de la conducta es sustancial o no. El

institution, as defined in section 1997 of this title, even if the burden results from a rule of general applicability, unless the government demonstrates that imposition of the burden on that person- (1) is in furtherance of a compelling governmental interest; and (2) is the least restrictive means of furthering that compelling governmental interest».

39 Véase supra nota 31.

4042 U.S.C.A. par. $2000 \mathrm{cc}-5$, define las prácticas religiosas como «any exercise of religion, whether or not compelled by, or central to, a system of religious belief». 
primer punto se satisface fácilmente, porque la religión es un concepto que en la práctica carece de límites: no existe test alguno que permita al juez evaluar si una determinada conducta es religiosa o no. Para abordar el segundo punto, los jueces cuentan con el test de la sustancialidad.

\section{EL TEST DE LA SUSTANCIALIDAD}

La determinación de la intensidad con que una creencia está siendo afectada enfrenta serias dificultades. Para ejemplificar esta cuestión utilizaremos la sentencia Sossamon v. Lone Star State of Texas ${ }^{41}$. Harvey Leroy Sossamon interpuso una acción invocando la RLUIPA contra una prisión estatal de Texas porque los oficiales de la prisión le prohibieron el acceso a la capilla de la cárcel para rezar. Para Sossamon, las diferentes posibilidades que se le ofrecieron para practicar su religión eran insuficientes, porque lo que él quería era arrodillarse frente a la cruz y el altar, y eso solo podía tener lugar en la capilla de la prisión. A primera vista al menos, la prohibición estaba justificada por razones de seguridad, pero antes de entrar a examinar si acaso esta era la forma menos lesiva de satisfacer un interés imperioso de la prisión, la Corte de Apelaciones del Quinto Circuito debía verificar si la limitación impuesta constituía realmente una restricción substancial de la libertad religiosa del demandante.

De acuerdo con la jurisprudencia del Quinto Circuito, «una restricción es substancial si realmente presiona al creyente a modificar su conducta religiosa y violenta significativamente sus creencias religiosas $»^{42}$. Es innecesario que la conducta o la creencia se refieran a un elemento central del sistema religioso del interesado. Basta con que el creyente «tenga una convicción honesta de que dicha práctica es importante para el ejercicio de su libertad religiosa ${ }^{43}$. Arrodillarse frente a la cruz y el altar para rezar era importante para Sossamon, de acuerdo con su personal concepción de la religión. Las alternativas ofrecidas por los oficiales de la prisión fracasaron: ninguna de ellas satisfizo «su necesidad de realizar lo que, aparentemente, eran aspectos importantes de su práctica del cristianismo» ${ }^{44}$. Puesto que los oficiales de la prisión prohibieron «la clase de adoración cristiana que Sossamon afirma como indispensable

\footnotetext{
41 Sossamon v. Lone Star State of Texas, 560 F.3d 316, 329 (5th Cir. 2009).

42 Sossamon v. Lone Star State of Texas, 560 F.3d 316, 332 (5th Cir. 2009).

43 Sossamon v. Lone Star State of Texas, 560 F.3d 316, 332 (5th Cir. 2009).

44 Sossamon v. Lone Star State of Texas, 560 F.3d 316, 333 (5th Cir. 2009) (énfasis en el original).
} 
para la práctica de $s u$ cristianismo» ${ }^{45}$, hay fundamentos para considerar que su libertad religiosa ha sido substancialmente restringida.

Podría pensarse que la ponderación de cuán sustancialmente es restringida la libertad religiosa de un prisionero ofrece un cierto marco de referencias objetivas, porque el test supone el binomio sustancial/accidental en relación al grado con que la libertad religiosa puede ser afectada. Luego, debería existir algún parámetro que permita distinguir unas limitaciones de otras. Dos criterios que han operado sobre esta base son el test de la centralidad y el test de la compulsividad ${ }^{46}$. El primero consiste en determinar qué tan central al sistema de creencias personales es la práctica religiosa que está motivando el conflicto. Así, el resultado es diferente si la excepción se requiere para acomodar una cuestión periférica, o un dogma, o una verdad esencial al credo o cosmovisión. Por su parte, el test de la compulsividad apunta a dilucidar el grado de observancia con que una determinada práctica es requerida por la propia fe. Igual que en el caso anterior, el resultado será diferente según si se trata de una práctica obligatoria u opcional.

No obstante, los test que miden la centralidad/marginalidad o la obligatoriedad/voluntariedad de una práctica religiosa carecen prácticamente de aplicación en tribunales hoy por hoy, debido a la incompatibilidad que esta clase de criterios tiene con la concepción tan amplia de libertad religiosa ${ }^{47}$. Una sentencia que ilustra el grado en que la extensión de la libertad religiosa priva de utilidad cualquier criterio como estos es Levitan $v$. Aschroft ${ }^{48}$.

En el caso Levitan v. Aschroft un grupo de presos católicos en una prisión federal en Pensacola iniciaron un juicio en contra del gobernador por aplicar una ley que prohibía el consumo de alcohol en el interior de la prisión, impidiéndoles como consecuencia comulgar con el vino consagrado durante la

45 Sossamon v. Lone Star State of Texas, 560 F.3d 316, 334 (5th Cir. 2009) (énfasis en el original).

46 Greenawalt (2006: 201-232).

47 Dos pruebas de esto son la sentencia Smith [«no hay principio legal ni lógico que pueda ser invocado para contradecir la afirmación de un creyente de que un acto particular es 'central' para su fe personal»: Employment Division, Department of Human Resources of Oregon v. Smith, 494 U.S. 872, 887 (1990)] y la definición de práctica religiosa en la RLUIPA (véase supra nota 40). Un ejemplo reciente es Daley v. Lappin (3d Cir., Jan. 29, 2014), en que se acogió la apelación contra la sentencia que, fundándose en que el vegetarianismo no es un mandamiento obligatorio de la religión rastafari, rechazó la excepción a un preso rastafari de una dieta vegetariana. No obstante, Gaubatz (2005: 527-532) identifica varios circuitos en que las Cortes de Apelaciones todavía aplican el test de la centralidad y de la compulsividad.

48 Levitan v. Ashcroft, 281 F.3d 1313, 1316 (D.C. Cir. 2002). 
misa. El juez de la Corte de Distrito rechazó la demanda porque, de acuerdo con la declaración de una monja católica y una carta del obispo católico de Pensacola, «la religión católica no requiere que los participantes consuman el vino en la comunión ${ }^{49}$. La Corte de Apelaciones, en cambio, revirtió la decisión considerando que «la exigencia de que una práctica religiosa sea obligatoria para que la Primera Enmienda la proteja no tiene fundamento alguno en la jurisprudencia de la Corte Suprema ${ }^{50}$. En su decisión, la Corte tuvo presente «la advertencia de la Corte Suprema acerca de la semejanza que media entre juzgar la centralidad de las diferentes prácticas religiosas y el negocio inaceptable de evaluar los méritos relativos de afirmaciones religiosas que difieren entre sí» ${ }^{51}$.

Lo dicho respecto de los test de la sinceridad y de la substancialidad vale también para el segundo factor de los cuatro definidos por la sentencia Turner v. Safley. Este factor indica al juez que para juzgar una determinada disposición penitenciaria a la luz de la libertad religiosa debe constatar si para los afectados por ella existen formas alternativas de practicar su religión. Pero, ¿cómo se determinará si una práctica religiosa admite formas alternativas? En un marco de referencias objetivas, esta determinación podría obtenerse como resultado de un proceso analítico, pero en un ámbito dominado por la subjetividad del prisionero el resultado dependerá absolutamente de lo que él considere sustituible ${ }^{52}$.

El test de la substancialidad es fácil de satisfacer en cualquier caso, porque los jueces no pueden echar mano de las distinciones entre lo que es religiosamente obligatorio/voluntario o de lo que es central/periférico dentro del sistema de creencias. De hecho, la RLUIPA recogió legalmente lo que ya era una práctica común en las Cortes con la Free Exercise Clause: el colapso del test de la substancialidad en el test de la sinceridad, dado que inhibe el uso de

49 Levitan v. Ashcroft, 281 F.3d 1313, 1316 (D.C. Cir. 2002).

50 Levitan v. Ashcroft, 281 F.3d 1313, 1319 (D.C. Cir. 2002).

51 Levitan v. Ashcroft, 281 F.3d 1313, 1320 (D.C. Cir. 2002). La referencia a la Corte Suprema corresponde a Employment Division, Department of Human Resources of Oregon v. Smith, 494 U. S. 872, 887 (1990).

52 Esto no debería significar que cualquier interferencia de actuaciones religiosamente motivadas pueda considerarse como una restricción sustancial a la libertad religiosa. Es lo que recuerda la sentencia en el caso United States $v$. Sterling (US Armed Forces Ct. App., Aug. 10, 2016), en la que se rechazó la demanda de una soldado obligada a retirar unos carteles con expresiones bíblicas que colocó fuera de su espacio de trabajo, porque es diferente afectar la sensibilidad religiosa que obligar a alguien a actuar en contra de lo que cree. 
cualquier parámetro de referencia para evaluar la intensidad de una restricción, aparte de las afirmaciones del propio interesado ${ }^{53}$.

\section{EL TEST DE LA SINCERIDAD}

Hay una distinción importante entre la fe sincera en unas verdades religiosas y la mera afirmación de dichas verdades. Los tribunales están familiarizados con esta distinción, especialmente en el contexto de las prisiones, en donde hay fuertes incentivos para la población encarcelada de aprovechar cualquier oportunidad para eximirse de las regulaciones generales. Los jueces son también conscientes del deber que tienen de proteger las demandas fundadas en una auténtica conciencia religiosa, para lo cual deben poderla distinguir de las falsas. Sin embargo, cuando se trata de trazar la línea entre una y otra y adjudicar una excepción, la distinción se hace muy complicada, si es que es posible. Determinar si la fe de alguien es sincera o no es una cuestión de hecho. Si la tarea en sí misma puede resultar muy complicada para quien deba establecer el hecho, esta deriva en la imposibilidad cuando es privada de toda referencia objetiva. ${ }^{54}$

Un caso que ilustra el problema para determinar la sinceridad es Patrick v. LeFevre. ${ }^{55}$ Vernon Patrick, un recluso miembro de la secta Five Percenters, inició un juicio invocando la Free Exercise Clause contra los oficiales de la prisión por su negativa a autorizar que su grupo religioso se reuniera para orar. Los oficiales demandados incoaron un juicio sumario (summary judgement) alegando que las creencias de Patrick no eran sinceras ni religiosas ${ }^{56}$. La Corte de Distrito decidió tramitar el juicio sumariamente sobre la base de esos antecedentes. Contra esa decisión, Vernon Patrick apeló.

53 Termine (2005: 222) celebra este resultado, porque «aplicar un estándar objetivo para determinar si acaso las creencias religiosas de alguien han sido afectadas sustancialmente, ignora tanto el concepto individualizado de religión como el lenguaje de la Primera Enmienda». Su (2016: 30) se refiere a la confusión entre estos dos elementos del estándar y los problemas que pueden seguirse.

54 Como resultado de esta hipersubjetivización, Sullivan (2005: 150) concluye que la religión se ha convertido en una categoría que ya no puede ser definida coherentemente para efectos del derecho norteamericano y, por lo tanto, inútil —aunque admite una reserva respecto de su valor retórico-.

55 Patrick v. LeFevre, 745 F.2d 153 (2d Cir. 1984).

56 Como indica el Black's Law Dictionary (2009), el summary judgement es una vía procesal para decidir una controversia en la que no existe una genuina diferencia acerca de los hechos, sino sólo acerca del derecho. Esta vía es una manera de evitar un juicio. 
A juicio de la Corte de Apelaciones del Segundo Circuito, la Corte de Distrito erradamente restringió la definición de "creencias religiosas», subestimando el factor subjetivo. En su sentencia hizo notar que una concepción de la religión basada en los contenidos de la misma ha sido abandonada por la jurisprudencia, dada su incompetencia para lidiar con asuntos que implican una interpretación de lo religioso. Una aproximación subjetiva, continuó la Corte de Apelaciones, es más conforme con la naturaleza secular del poder judicial, cuyo rol es proteger la libertad religiosa de interferencias ilegítimas, "allí hasta donde el demandante concibe sus creencias como religiosas" ${ }^{57}$.

Esta aproximación subjetiva defendida en la sentencia Patrick v. LeFevre implica, en opinión de la Corte, un cuidadoso examen de "las actitudes internas del individuo hacia un sistema particular de creencias» ${ }^{58}$. En otras palabras, las creencias religiosas no deberían ser desestimadas en función de consideraciones basadas en referencias objetivas. Esto implica que las alegaciones de la autoridad para demostrar que la secta de los Five Percenters no es una religión (por ejemplo, la inexistencia de un lugar ni un tiempo específico de reunión para rezar, el que sus miembros se adoran a sí mismos y la ausencia de canales estructurados para expresar sus creencias) deben ser rechazadas por la Corte.

Una concepción enteramente subjetiva de la religión domina el razonamiento de la Corte de Apelaciones en la sentencia Patrick v. LeFevre. De acuerdo con una aproximación como esta, los jueces deben «sumergirse en los vericuetos de la mente del demandante para ponderar la credibilidad de sus afirmaciones $\aleph^{59}$. En esta operación, claro está, los jueces deben abstenerse de referencias objetivas, limitándose a confrontar «las manifestaciones subjetivas de la sinceridad con que se cree con la naturaleza de lo que puede percibirse de tales creencias» ${ }^{60}$. Esta manera de concebir la religión priva a los jueces de cualquier criterio útil para distinguir aquellas creencias protegidas por la Free Exercise Clause o la RLUIPA de aquellas que no lo están ${ }^{61}$.

\footnotetext{
Patrick v. LeFevre, 745 F.2d 153, 159 (2d Cir. 1984).

Patrick v. LeFevre, 745 F.2d 153, 159 (2d Cir. 1984).

Patrick v. LeFevre, 745 F.2d 153, 159 (2d Cir. 1984).

60 Patrick v. LeFevre, 745 F.2d 153, 159 (2d Cir. 1984).

61 Boston y Manville (2010: 255) constatan lo obvio: «Las cortes generalmente recelan de declarar simuladas las creencias en summary judgement». Adams y Barmore (2014) advierten la necesidad de limitar la protección de la libertad religiosa frente a cualquier reclamo de conciencia sincero. ¿Cómo? "La respuesta está en la objetividad", afirman. Al mismo tiempo, admiten que esta respuesta "lleva aparejada el riesgo de que las cortes se deslicen impropiamente hacia cuestiones de veracidad y centralidad».
} 
Dada la prohibición que grava a los jueces de inmiscuirse en los contenidos religiosos, podría estimarse que una forma viable de verificar la sinceridad de las creencias es ponderar las conductas del interesado a la luz de sus creencias personales. Puesto que, en principio, una fe auténtica se expresa en una conducta consistente con dicha fe, la investigación podría indagar en el historial del prisionero a fin de conocer si existe esa consistencia entre fe/conciencia y conducta. La ventaja teórica de este camino es que corre paralelo a cualquier argumento religioso; para conducirse exitósamente en él solo se precisa contrastar lo que se dice con lo que se hace. Sin embargo, este ejercicio también se revela inútil en la práctica. La sentencia Lovelace v. Lee es un buen ejemplo de esto ${ }^{62}$.

Leroy Lovelace, un musulmán encarcelado en una prisión del estado de Virginia, fue removido de la lista de personas autorizadas para participar en las comidas de Ramadán. El motivo de su remoción fue que, de acuerdo con el criterio de los oficiales de la prisión, la fe de Lovelace era insincera, porque había quebrantado el ayuno de Ramadán. Lovelace demandó alegando que su exclusión de la excepción hecha con los musulmanes, consistente en una oración conjunta y comidas especiales, restringió substancialmente su libertad religiosa. Si bien la Corte en su sentencia admitió que «los oficiales de la prisión pueden con razón preguntarse si la religiosidad de un prisionero, en cuanto condición básica para conceder una excepción, es auténtica o no» ${ }^{63}$, al excluir a Lovelace por la inconsistencia entre su palabra y su conducta, pasaron por alto el hecho de que el prisionero «puede decidir no vivir su religión respecto del ayuno y sí vivirla en otros aspectos ${ }^{64}$. Consecuentemente, siguió la Corte, los oficiales de la prisión se equivocaron al asumir que «la ausencia de sinceridad (o de religiosidad) con respecto a una práctica significa [automáticamente] falta de sinceridad con respecto a otras prácticas» ${ }^{65}$. Así, aunque la conducta del propio Lovelace gatilló su exclusión de la acomodación religiosa, puede acogerse la demanda en virtud de la RLUIPA porque su libertad religiosa fue substancialmente afectada ${ }^{66}$.

62 Lovelace v. Lee, 472 F.3d 174 (4th Cir. 2006).

63 Lovelace v. Lee, 472 F.3d 174, 188 (4th Cir. 2006). El test de la sinceridad no debe llevarnos a pensar que se satisface con las meras alegaciones del interesado de que sus creencias son sinceras. De hecho, se rechazan demandas porque no se ha podido demostrar la sinceridad. Por ejemplo, Gardnerv. Riska, 444 F. App'x 353 (11th Cir. 2011).

64 Lovelace v. Lee, 472 F.3d 174, 188 (4th Cir. 2006).

65 Lovelace v. Lee, 472 F.3d 174, 188 (4th Cir. 2006).

66 Lovelace v. Lee, 472 F.3d 174, 188 (4th Cir. 2006). 
En definitiva, los elementos de la parte subjetiva de la fórmula de acomodaciones religiosas naufragan ante la ausencia de referencias externas a las declaraciones de los presos ${ }^{67}$. El juicio acerca de la sustancialidad de una determinada expresión religiosa es irremediablemente conducido hacia el juicio acerca de la sinceridad de una determinada creencia, y el juicio de la sinceridad está desprovisto de toda referencia objetiva ${ }^{68}$. No sorprende, por lo tanto, que Greenawalt aconseje «aproximaciones alternativas» para eludir el test de la sinceridad, siempre que sea posible: "Las complejidades de determinar la sinceridad ofrecen una razón para que se elija "la segunda mejor opción" entre los estándares legales [para proteger la libertad religiosa]» (Greenawalt, 2006: 109). La parte objetiva de la fórmula de acomodación es precisamente esa «aproximación alternativa», preferida tanto por los agentes penitenciarios como por los jueces.

\section{EL JUICIO DE LA DIMENSIÓN OBJETIVA}

Esta sección aborda los elementos objetivos contenidos en los estándares de acomodación de la Free Exercise Clause y de la RLUIPA.

\section{LA CONEXIÓN RACIONAL ENTRE LA REGULACIÓN Y LOS INTERESES DE LA PRISIÓN}

De acuerdo a la sentencia Turner, el primer factor establece que «la regulación [carcelaria] es válida si es que tiene un vínculo razonable con un interés penológico legítimo» ${ }^{69}$. Esto implica para los jueces elucidar «si acaso hay una

67 Como consecuencia de esto puede entenderse la conclusión de Su (2016: 43-44): "Actualmente no existe una teoría general o definición por la cual entender la carga substancial sobre la religión [...]; no hay al presente una vía predecible para determinar legalmente lo que constituye una carga [sobre la libertad religiosa]».

$68 \mathrm{Su}$ (2016: 41-42) matiza los efectos de esta conclusión señalando que la familiaridad del juez con una determinada práctica religiosa facilita significativamente la "prueba» de la sinceridad: «Es fácil creer que alguien es sincero respecto de una creencia particular, si tal creencia es inteligible para la corte».

69 Turner v. Safley, 482 U.S. 78, 89, 107 S. Ct. 2254, 2261, 96 L. Ed. 2 d 64 (1987). El vínculo entre la regulación y los intereses puede conocer varios adjetivos: racional, [Nasir v. Morgan, 350 F.3d 366, 371 (3d Cir. 2003)], válido [Frost v. Symington, 197 F.3d 348, 354 (9th Cir. 1999)], esencial [Walker v. Gomez, 370 F.3d 969, 977 
conexión válida, racional, entre las regulaciones de la prisión y el interés defendido por el gobierno, o si por el contrario este interés es tan remoto que convierte la política en arbitraria o irracional $\aleph^{70}$. De ordinario, las controversias giran en torno a necesidades justificadas por la seguridad del penal, la higiene, la integridad de presos y guardias o la disciplina. La casuística en este punto es grande.

Aquí no interesa tanto precisar lo que los tribunales entienden por una conexión racional, razonable, lógica o válida entre una determinada disposición y la finalidad que estaría justificándola, sino más bien subrayar la naturaleza secular del razonamiento necesario para juzgar esa relación. Así, por ejemplo, la prohibición de dejarse crecer pelo en la cara y la eventual excepción de esta regla para judíos jasídicos se decidirá en función de las implicancias de higiene y seguridad que pueda tener para el penal la existencia de presos barbados, y no de acuerdo a la significación religiosa que la barba tiene para los miembros del judaísmo jasídico ${ }^{71}$. Lo mismo vale para disposiciones acerca del largo del cabello ${ }^{72}$, de medidas especiales para prisoneros de alto riesgo $^{73}$, del uso de túnicas ${ }^{74}$, del uso de la sauna ${ }^{75}$ y de la predicación ${ }^{76}$, por mencionar algunos. Un caso que ilustra el punto es Washington $v$. Klem ${ }^{77}$, en el que un preso recurrió a tribunales en contra de una disposición que limitaba a diez el número de libros que un encarcelado podía tener en su celda. De acuerdo a su religión, Henry Washington debía leer cuatro libros afrocéntricos diarios; el lugar de estos libros en su religión era tal que «sus libros y su religión eran lo mismo ${ }^{78}$. Pese a que la demanda de Washington se acogió porque la disposición afectaba sustancialmente a su libertad religiosa, lo decisivo en este caso fue la incapacidad de la autoridad para demostrar que la desinfección de las celdas y la prevención de incendios, contrabando y ocultamiento de armas exigieran un máximo de diez libros por celda.

(9th Cir. 2004)], lógico [Victoria W. v. Larpenter, 369 F.3d 475, 484 (5th Cir. 2004)]. Pi-wei (2004: 1156) señala las debilidades del estándar de razonabilidad en el contexto de las excepciones alimentarias, y propone un enfoque que lo refuerce.

70 Wall v. Wade, 741 F.3d 492, 499 (4th Cir. 2014).

71 Flagner v. Wilkinson, 241 F.3d 475 (6th Cir. 2001).

72 Smith v. Ozmint, 578 F.3d 246 (4th Cir. 2009) o Knight v. Thompson, 723 F.3d 1275 (11th Cir. 2013).

73 Fraise v. Terhune, 283 F.3d 506, 517 (3d Cir. 2002).

74 Abdullah v. Kinnison, 769 F.2d 345 (6th Cir. 1985).

75 Allen v. Toombs, 827 F.2d 563 (9th Cir. 1987)

76 Spratt v. Rhode Island Dept. of Corr., 482 F.3d 33 (1st Cir. 2007).

77 Washington v. Klem (3d Cir., Aug. 2, 2007).

78 Washington v. Klem, 282 (3d Cir., Aug. 2, 2007). 


\section{EL IMPACTO DE LA EXCEPCIÓN EN LA COMUNIDAD PENITENCIARIA}

Otro factor de la dimensión objetiva de la fórmula de acomodación consiste en ponderar las implicancias que una excepción representa para la comunidad penitenciaria, considerando al conjunto de los prisioneros, al cuerpo de oficiales y la distribución de los recursos del penal ${ }^{79}$. La consideración de estas variables por parte del juez lo sitúa en un plano esencialmente secular, definido por criterios de administración carcelaria. Un ejemplo que ilustra bien lo anterior es DeHart v. Horn. ${ }^{80}$

Robert P. DeHart es un budista que cumple cadena perpetua en una prisión estatal de Pennsylvania. Él defiende que su religión le exige observar una dieta vegetariana, por lo que solicitó que se le hiciera una excepción por motivos religiosos. Los oficiales de la prisión rehusaron concedérsela aplicando el test de la compulsividad: el vegetarianismo no es exigido "por ninguna de las sectas budistas reconocidas ${ }^{81}$. DeHart demandó y la Corte de Circuito dispuso que se viera en juicio sumario (generalmente más favorable a los oficiales de la prisión). DeHart apeló la decisión del juez y la Corte de Apelaciones revirtió la decisión apelada porque el tribunal inferior ignoró la disputa sobre el impacto que la acomodación solicitada habría tenido en la comunidad del penal ${ }^{82}$. La cuestión abordada por la Corte no fue acerca de si la negativa de una dieta vegetariana afectaba substancialmente la libertad religiosa del prisionero, sino si acaso el añadir una taza de leche de soja en su régimen habría tenido un impacto inadmisible en la comunidad penal. DeHart alegó que la acomodación por él solicitada se satisfaría sencillamente con el complemento líquido, y que resultaba difícil de creer que dicho complemento impusiera una severa carga sobre la administración del penal, al menos en términos económicos; esto especialmente considerando el precio de la dieta kosher que de forma voluntaria la administración sirve a los presos de religión judía. Como señaló la Corte, «el trato que los demandados prodigan a los presos judíos [...] arroja dudas importantes sobre el argumento de que acomodarse a la solicitud del preso DeHart representaría problemas serios para la comunidad de la prisión» ${ }^{83}$. De esto modo, la Corte de

\footnotetext{
Wall v. Wade, 741 F.3d 492, 499 (4th Cir. 2014).

DeHart v. Horn, 227 F.3d 47 (3d Cir. 2000).

DeHart v. Horn, 227 F.3d 47, 49 (3d Cir. 2000).

82 La Corte corrigió la sentencia apelada hacienda notar que el test de la compulsividad descansa en una distinción que es inconsistente con la jurisprudencia de la Corte Suprema y, en consecuencia, no debe utilizarse en la aplicación del segundo de los criterios de Turner. DeHart v. Horn, 227 F.3d 47, 54 (3d Cir. 2000).

83 DeHart v. Horn, 227 F.3d 47, 58 (3d Cir. 2000).
} 
Apelaciones le ordenó al tribunal inferior que volviera a estudiar el caso, específicamente si la compra de 225 gr. de leche de soja diaria supondría una carga demasiado pesada sobre la administración del penal.

Acomodar el ejercicio de la libertad religiosa de DeHart vino a decidirse en un terreno ajeno al religioso. Cuán sinceramente DeHart creía en la significación religiosa del vegetarianismo, qué importancia tenía la práctica del vegetarianismo para DeHart, o qué lugar ocupa el vegetarianismo en el conjunto de las creencias budistas fueron todas cuestiones prácticamente irrelevantes en la discusión. Debido a que la libertad religiosa opera como una categoría que priva a los jueces del instrumental necesario para sostener una argumentación contra la subjetividad del prisionero, la decisión estriba en una cuestión mucho más mundana como lo es la del impacto que la compra de una taza de leche de soja al día representa para el presupuesto del penal.

\section{EL TEST DEL COSTO MÍNIMO}

Un tercer factor consiste en verificar la existencia de formas alternativas de acomodarse a la necesidad religiosa del prisionero, a un costo mínimo para los intereses legítimos de la prisión ${ }^{84}$. Si estas formas alternativas existen, entonces la regulación que limita la libertad religiosa será considerada desproporcionada o poco razonable ${ }^{85}$. La evaluación del costo mínimo está asociada a la fácil y rápida disponibilidad de esas formas alternativas ${ }^{86}$. Demostrar la existencia de estas alternativas es una carga del prisionero ${ }^{87}$.

En el caso Shakur v. Schriro un musulmán demandó a los oficiales de la prisión invocando la Free Exercise Clause y la RLUIPA ${ }^{88}$. Pedía que se le diera una comida kosher puesto que, por razones médicas, estaba impedido de seguir la dieta halal. A la luz de la Free Exercise Clause, la Corte de Apelaciones revirtió la decisión del tribunal inferior de resolver el caso en juicio sumario, porque los demandados no habrían satisfecho la exigencia del cuarto

84 Este criterio — costo de minimis - está también presente, por ejemplo, en el título VII de la Civil Rights Act (1967): cuando acomodarse a las necesidades religiosas del empleado representa más que un costo mínimo para el empleador, entonces no hay fundamento para demandar por discriminación arbitraria. Por ejemplo, E.E.O.C. v. GEO Grp., Inc., 616 F.3d 265 (3d Cir. 2010).

85 Turner v. Safley, 482 U.S. 78, 90, 107 (1987).

86 Turner v. Safley, 482 U.S. 78, 80 (1987).

87 Turner v. Safley, 482 U.S. 78, 80 (1987).

88 Shakur v. Schriro, 514 F.3d 878, 887-88 (9th Cir. 2008). 
factor del test de Turner. Los oficiales de la prisión alegaron que acomodarse a la solicitud de Shakur hubiera representado un costo más que mínimo sobre el presupuesto de la prisión. Sin embargo, no aportaron ninguna evidencia en este sentido. Por otra parte, los antecedentes enseñaban que en la cárcel existían dos regímenes kosher diferentes, disponibles para los presos judíos. Uno de ellos era cinco dólares más caro que el régimen estándar diario, y el otro era entre tres y cinco veces más caro. La conclusión cayó por su propio peso: si la prisión puede pagarlos para los presos judíos, ¿por qué no podría pagarlos para los presos musulmanes? Puesto que los oficiales de la prisión fueron incapaces de explicar cómo el incremento de una dieta kosher impondría un costo inaceptable, la Corte «está impedida de resolver si la dieta solicitada por Shakur representa más que un costo de minimis» sobre la prisión ${ }^{89}$. En definitiva, se le ordenó a la Corte de Distrito que volviera a estudiar el asunto, indagando acerca de la existencia de formas alternativas para acomodarse a las necesidades religiosas de Shakur.

El test del costo mínimo no está confinado a consideraciones directamente económicas de manera exclusiva ${ }^{90}$. El valor ejemplar del caso Shakur v. Schriro es que enseña la naturaleza del razonamiento envuelto en este factor del test de Turner, en que la cuestión se centró en el impacto que cinco dólares diarios tienen en el presupuesto del penal. ${ }^{91}$

\section{EL TEST DEL INTERÉS IMPERIOSO}

Como se dijo más arriba, la RLUIPA excusa al Gobierno de restringir substancialmente la libertad religiosa de alguien, siempre y cuando dicha restrición «obedezca a un interés gubernamental imperioso y sea el medio menos lesivo para satisfacerlo»" ${ }^{92}$.

En un caso de 2014, Yellowbear v. Lampert ${ }^{93}$, la Corte de Apelaciones del Décimo Circuito también operó en el terreno de las consideraciones objetivas para decidir sobre una excepción religiosa. Andrew J. Yellowbear es un preso

\footnotetext{
89 Shakur v. Schriro, 514 F.3d 878, 887-88 (9th Cir. 2008).

90 Por ejemplo, Mauro v. Arpaio, 188 F.3d 1054 (9th Cir. 1999), en que se discutió el costo que tendría en términos de seguridad para oficiales mujeres la habilitación de una sala de lectura de material sexual explícito.

91 Liu (2004: 1172) apunta las diferencias de criterio entre las cortes de los distintos circuitos acerca de cuándo el costo es de minimis.

9242 U.S.C. $\$ 2000 \mathrm{cc}-1$ (a).

93 Yellowbear v. Lampert, 741 F.3d 48 (10th Cir. 2014).
} 
condenado a cadena perpetua. Como miembro de la tribu indígena Northern Arapaho, reclama que su religión incluye frecuentar la sauna (sweat lodge). Los oficiales de la prisión, sin embargo, le negaron el acceso a la sauna de la cárcel, alegando motivos de seguridad y presupuestarios. Al tiempo del juicio, Yellowbear estaba encerrado en una unidad especial para protegerlo del resto de los prisioneros, por lo que trasladarlo a la sauna suponía medidas extraordinarias. Aplicando el estándar de la RLUIPA, la Corte tuvo que examinar si la solicitud de Yellowbear era efectivamente religiosa y si la negativa de la prisión imponía una restricción substancial a su religión. Por otra parte, debía averiguar si la decisión de los oficiales de la prisión estaba motivada por un interés imperioso y representaba el medio menos lesivo de satisfacerlo. En relación a los dos primeros elementos del estándar, los subjetivos, la Corte los dio por establecidos sin discusión ni dificultad: los oficiales de la prisión no discutieron ni el carácter religioso de la sauna para Yellowbear ni la sinceridad de su fe. El debate se trasladó, por lo tanto, a los aspectos objetivos de la fórmula. En relación al «interés imperioso", los representantes de la prisión ofrecieron tres argumentos. En primer lugar, que «las saunas implican el uso de carbones calientes y fuego, por lo que hay un factor de riesgo inherente en ellos en el contexto de una prisión (y la reducción del riesgo es inviable a un costo mínimo)»»'. La Corte desechó este argumento porque los antecedentes enseñan "que la operación actual de la sauna de la prisión no es problemática en ningún sentido»". En segundo lugar, argumentaron que trasladar al prisionero de ida y vuelta desde su unidad a la sauna tenía «implicancias económicas y administrativas»: había que encerrar a una buena parte de los presos para evitar que se lanzaran sobre Yellowbear. La Corte tampoco consideró válido este argumento, por dos motivos. Primero, porque «los demandados ni siquiera han intentado cuantificar los costos implicados, ni menos aún cómo esos costos afectan el presupuesto o la administración del penal $»^{96}$. Segundo, los oficiales de la prisión no proveyeron ninguna explicación satisfactoria para justificar la negativa a encerrar a parte de los presos para acomodarse a la exigencia religiosa de Yellowbear, máxime cuando esto es algo que hacen con frecuencia por motivos «seculares», como el transporte de personas por razones médicas. La Corte seńaló que «en este caso los oficiales de la prisión no han hecho ningún esfuerzo para refutar la evidencia presentada por Yellowbear sobre la discriminación en su contra ${ }^{97}$. En tercer lugar, los oficiales de la prisión recurrieron al argumento de la pendiente resbaladiza para demostrar el

\footnotetext{
94 Yellowbear v. Lampert, 741 F.3d 48, $57-58$ (10th Cir. 2014).

95 Yellowbear v. Lampert, 741 F.3d 48, 58 (10th Cir. 2014).

96 Yellowbear v. Lampert, 741 F.3d 48, 59 (10th Cir. 2014).

97 Yellowbear v. Lampert, 741 F.3d 48, 61 (10th Cir. 2014).
} 
interés imperioso que los motivaba: si accedían a la petición de Yellowbear, se verían inundados de peticiones similares de parte de los demás presos. Pero, una vez más, la Corte desestimó el argumento, porque no hay antecedentes que sugieran «la existencia de otros presos interesados en unirse a Yellowbear o que, si los hubiera, el acomodarlos restringiría seriamente los recursos de la prisión ${ }^{98}$.

Yellowbear $v$. Lampert es un ejemplo elocuente del terreno en el que se deciden las excepciones religiosas para los presos. Como nos enseña este caso, los elementos subjetivos de la fórmula de la RLUIPA están fuera del núcleo de la discusión. La atención está puesta en los componentes objetivos de la fórmula de acomodación. La decisión finalmente pivota en el test del interés imperioso, con independencia de consideraciones religiosas. Lo que inclinó decisivamente la balanza en favor de Yellowbear fue la falta de pruebas que sustentaran las aprensiones administrativas y de seguridad de los oficiales de la prisión. Los demandados no hicieron nada para demostrar que lo que sí estaban dispuestos a hacer por motivos médicos (por ejemplo, cerrar a los presos en sus celdas para trasladar a un enfermo) se justificaba negarlo a Yellowbear, que invocaba motivos religiosos. Los jueces admiten la opción de que esta discriminación se apoye en un interés imperioso de la autoridad, pero tienen el deber de argumentarla99. La Corte es indiferente a la distinción filosófica que media entre las necesidades médicas y las prácticas religiosas. Si se la hubiera presionado para que se pronuncie sobre ella, habría eludido la cuestión afirmando que los jueces no están equipados para responder qué es más importante, si la vida del cuerpo o la vida del alma. En cambio, la Corte parece cómoda moviéndose en el terreno de las consideraciones económicas.

\section{EL TEST DE LA LESIVIDAD}

No es infrecuente que las regulaciones penitenciarias atacadas caigan bajo el peso del segundo de los componentes objetivos del estándar de la RLUIPA, esto es, la existencia de medios menos lesivos para satisfacer el interés imperioso invocado ${ }^{100}$. En el caso Spratt v. Rhode Island Dept. of Correc-

98 Yellowbear v. Lampert, 741 F.3d 48, 62 (10th Cir. 2014).

99 Yellowbear v. Lampert, 741 F.3d 48, 61-62 (10th Cir. 2014).

100 Aunque se parece, no debe ser confundido con el test del costo mínimo. Fortner v. Thomas, 983 F.2d 1024, 1030 (11th Cir. 1993): «Enfatizamos que el cuarto factor de Turner no es un test "de la alternativa menos restrictiva”". En cambio, es fácil detectar la similitud que guarda con el factor de Turner que requiere la existencia de formas alternativas para practicar la religión. Aunque difieren en el grado de escrutinio aplicado a la 
tions la Corte de Apelaciones del Quinto Circuito concedió con cierta cautela que la prohibición de predicar que recayó sobre un preso estaba inspirada por una necesidad imperiosa por conservar la seguridad del penal. Sin embargo, puesto que la prohibición no era la forma menos lesiva de garantizar la seguridad del establecimiento, la Corte decidió en favor de Spratt. El razonamiento del tribunal desarmó la supuesta eficacia de la prohibición en relación a la seguridad de la cárcel, basándose en consideraciones que poco o nada tienen que ver con cuestiones subjetivas. En un conjunto de preguntas dirigidas a la dudosa eficacia de la disposición adoptada por los oficiales de la prisión, la Corte puso al desnudo lo insostenible de la posición de los demandados:

¿Por qué se le prohibe a un preso predicar, cuando se les permite liderar a sus compañeros en otras circunstancias? Del mismo modo, ¿por qué se le permite [a Spratt] pararse en frente de sus correligionarios y leer las escrituras, si es que es su presencia en el púlpito lo que resulta problemático? Si el aspecto instruccional/pedagógico de las escrituras es tan problemático, ¿por qué se autoriza a los presos asistir a programas educacionales dentro de la prisión? ¿Por qué autorizar la predicación bajo una estricta supervisión policial sería una solución menos efectiva para satisfacer el propósito de seguridad del penal? ${ }^{101}$.

Los oficiales de la prisión fueron incapaces de contestar estas preguntas, por lo que la prohibición de predicar quedó injustificada en cuanto medio para garantizar la seguridad del penal, lesionando lo menos posible la libertad religiosa de Spratt. En adición a esto, la Corte trajo a colación las políticas de la Federal Bureau of Prisons, que admitirían excepciones respecto de la predicación de los presos. De este modo, descubriendo las inconsistencias entre la prohibición

restricción de la libertad religiosa (la RLUIPA es más exigente que la Free Exercise Clause), comparten la perspectiva: ambas implican un cuestionamiento táctito acerca del lugar que ocupa una determinada práctica religiosa en la subjetividad del preso. En este sentido, es fácil que el test de la sustancialidad y el test de lesividad puedan convertirse en (o ser entendidos como) las dos caras de una misma moneda (Lupu y Tuttle, 2011: 1932). Si acaso es posible separar absolutamente el test de lesividad del medio empleado de toda consideración religiosa, es algo que declinamos abordar aquí. Lupu y Tuttle (2011: 1934) piensan que sí es posible. De hecho, su propuesta es «permitir a los prisioneros el espacio para declarar por sí mismos la intensidad de la restricción que están experimentando en su ejercicio de la religión y, simultáneamente, garantizar a los oficiales de la prisión una ampia autoridad para definir materias concernientes a la integridad de los reclusos, la seguridad, y los recursos siempre limitados, como motivos para rehusarse a hacer excepciones por motivos religiosos» (Lupu y Tuttle, 2011: 1935).

101 Spratt v. Rhode Island Dept. of Corr., 482 F.3d 33, 42 (1st Cir. 2007). 
de predicar y la necesidad de garantizar la seguridad del penal, el tribunal concluyó que la prohibición en este caso no satisfacía el test de lesividad.

\section{CONCLUSIÓN}

La protección judicial de la libertad religiosa en las cárceles de los EE. UU. enseńa que, al menos en el discurso, el concepto de religión se ha diluido en la pura subjetividad individual. Este resultado se infiere de la improcedencia de referencias objetivas que permitan definir la naturaleza religiosa de una práctica determinada. La consecuencia que se sigue de esto es que el centro de la discusión acerca del alcance de la libertad religiosa se desplaza desde lo que es una práctica religiosa legítima hacia lo que resulta razonable para administrar el penal (en términos económicos, disciplinarios, higénicos, etc.). Este cambio puede interpretarse como signo del debilitamiento de la libertad religiosa, en cuanto la religión se revela como una categoría inútil para precisar el ámbito de la libertad para practicarla. Es lógico, por tanto, que una parte del debate acerca de la libertad religiosa en los Estados Unidos discuta la justificación de la protección que la Constitución le garantiza: si se trata de una libertad cuyo contenido es imposible de precisar, quizá sea porque estamos frente a una libertad sin contenido. Si este fuera el caso, ¿por qué habría de protegerse?

\section{Bibliografía}

Adams, B. y Barmore, C. (2014). Questioning Sincerity. The Role of the Courts After Hobby Lobby. Stanford Law Review Online, 67, 59-6. Disponible en: https://stanford.io/2JQc2La. Black's Law Dictionary. (2009). (9 $9^{\text {th }}$ ed.).

Boston, J. y Manville, D. E. (2010). Prisoners' Self-Help Litigation Manual. Oxford: Oxford University Press.

Brady, K. L. (2011). Religious Sincerity and Imperfection: Can Lapsing Prisoners Recover Under RFRA and RLUIPA? University of Chicago Law Review, 78, 1431-1464.

Committee on the Judiciary United States House of Representatives. (1993). House of Representatives Report no. 103-111. Disponible en: https://bit.ly/2HwhmhL.

Committee on the Judiciary United States Senate. (1993). Senate Report no. 103-111. Disponible en https://bit.ly/2LyyfuK.

Committee on the Judiciary United States Senate. (1997). Congress' constitutional role in protecting religious liberty. Washington: U.S. Government Printing Office. Disponible en: https://bit.ly/2xTaYl3.

Cooper, A. (1995). Dam the RFRA at the prison gate: The religious freedom restoration act's impact on correctional litigation. Montana Law Review, 56 (1), 325-348. 
Eisgruber, C. y Seager, L. (2009). Religious Freedom and the Constitution. Boston: Harvard University Press.

Gaubatz, D. L. (2005). RLUIPA at four: Evaluating the success and constitutionality of RLUIPA's prisoner provisions. Harvard Journal of Law Public Policy, 28 (2), 501-608.

Greenawalt, K. (2006). Religion and the Constitution, vol. 1. Free Exercise and Fairness. Princeton: Princeton University Press.

Haas, K. C. (1977). Judicial politics and correctional reform: An analysis of the decline of the hands-off doctrine. Detroit College of Law Review, 4, 795-832.

Liu, B. (2004). Prisoner's Right to Religious Diet beyond the Free Exercise Clause. UCLA Law Review, 51 (4), 1151-1202.

Lupu, I. C. (1998). The Failure of RFRA. University of Arkansas at Little Rock Law Journal, 20, 575-617.

- y Tuttle, R. W. (2011). The forms and limits of religious accommodation: The case of RLUIPA. Cardozo Law Review, 32 (5), 1907-1936.

McDonald, F. (1985). Novus ordo seclorum: the intellectual origins of the Constitution. Kansas: University Press of Kansas.

McConnell, M. (1985). Accomodation of Religion. Supreme Court Review, 1985, 1-60.

- (1992). Accommodation of Religion: An Update and Response to the Critics. George Washington Law Review, 60 (3), 685-742.

—, Garvey, J. y Berg, T. (2011). Religion and the Constitution. New York: Aspen Publishers.

Palmer, J. W. (2010). Constitutional Rights of Prisioners. Abingdon: Routledge.

Paulsen, M. S. (1995). RFRA Runs through It: Religious Freedom and the U.S. Code. Montana Law Review, 56 (1), 249-294.

— y Paulsen, L. (2015). The Constitution: An introduction. Philadelphia: Basic Books.

Pi-wei Liu, B. (2004). A Prisoner's right to religious diet beyond the Free Exercise Clause. UCLA Law Review, 51, 1151-1201.

Scalia, J. (2002). Prisoner Petitions Filed in U.S. District Courts, 2000, with Trends 19802000. Bureau of Justice Statistics. Disponible en: https://bit.ly/2JwZYi7.

Smith, T. (2016). Religious Liberty or Religious License: Legal Schizophrenia and the Case against Examptions. Journal of Law Politics, 32 (1), 43-94.

Solove, D. J. (1996). Faith profaned: The religious freedom restoration act and religion in the prisons. Yale Law Journal, 106 (2), 459-492.

Su, A. (2016). Judging Religious Sincerity. Oxford Journal of Law and Religion, 5, 28-48.

Sullivan, W. F. (2005). The Impossibility of Religious Freedom. Princeton: Princeton University Press.

Termine, K. (2005). Ford v. McGinnis: Should courts really enter the thicket of theology. Quinnipiac Law Review, 24 (1), 187-226.

\section{Jurisprudencia}

Abdullah v. Kinnison, 769 F.2d 345 (6th Cir. 1985).

Allen v. Toombs, 827 F.2d 563 (9th Cir. 1987).

City of Boerne v. Flores, 521 U.S. 507 (1997). 
Cooper v. Pate, 378 U.S. 546 (1964).

Cruz v. Beto, 405 U.S. 319 (1972).

Daley v. Lappin (3d Cir., Jan. 29, 2014).

DeHart v. Horn, 227 F.3d 47 (3d Cir. 2000).

E.E.O.C. v. GEO Grp. Inc., 616 F.3d 265 (3d Cir. 2010).

Employment Division, Department of Human Resources of Oregon v. Smith, 494 U.S. 872 (1990).

Flagner v. Wilkinson, 241 F.3d 475 (6th Cir. 2001).

Fortner v. Thomas, 983 F.2d 1024 (11th Cir. 1993).

Fraise v. Terhune, 283 F.3d 506 (3d Cir. 2002).

Frost v. Symington, 197 F.3d 348 (9th Cir. 1999).

Gardner v. Riska, 444 F. App’x 353 (11th Cir. 2011).

Haas v. United States, 344 F.2d 56 (8th Cir. 1965).

Jones v. North Carolina Prisoners' Labor Union, Inc., 433 U.S. 119 (1977).

Knight v. Thompson, 723 F.3d 1275 (11th Cir. 2013).

Koger v. Bryan, 523 F.3d 789 (7th Cir.2008).

Levitan v. Ashcroft, 281 F.3d 1313 (D.C. Cir. 2002).

Lovelace v. Lee, 472 F.3d 174 (4th Cir. 2006).

Mauro v. Arpaio, 188 F.3d 1054 (9th Cir. 1999).

Mormon Church v. United States, 136 U.S. 1 (1890).

Nasir v. Morgan, 350 F.3d 366 (3d Cir. 2003).

O'Lone v. Estate of Shabazz, 482 U.S. 342 (1987).

Patrick v. LeFevre, 745 F.2d 153 (2d Cir. 1984).

Pell v. Procunier, 417 U.S. 817 (1974).

Price v. Johnston, 334 U.S. 266 (1948).

Reynolds v. United States, 98 U.S. 145 (1878).

Ruffin v. Commonwealth, 62 Va. 790 (1871).

Shakur v. Schriro, 514 F.3d 878 (9th Cir. 2008).

Smith v. Ozmint, 578 F.3d 246 (4th Cir. 2009).

Sossamon v. Lone Star State of Texas, 560 F.3d 316 (5th Cir. 2009).

Spratt v. Rhode Island Dept. of Corr., 482 F.3d 33 (1st Cir. 2007).

Thomas v. Indiana Employment Security Division 450 U.S. 707 (1981).

Turner v. Safley, 482 U.S. 78 (1987).

United States v. Ballard, 322 U.S. 78 (1944).

United States v. Seeger 380 U.S. 163 (1965).

United States v. Sterling (US Armed Forces Ct. App., Aug. 10, 2016).

Victoria W. v. Larpenter, 369 F.3d 475 (5th Cir. 2004).

Walker v. Gomez, 370 F.3d 969 (9th Cir. 2004).

Wall v. Wade, 741 F.3d 492 (4th Cir. 2014).

Washington v. Klem (3d Cir., Aug. 2, 2007).

Yellowbear v. Lampert, 741 F.3d 48 (10th Cir. 2014). 